\title{
Vitamin D status in growing dairy goats and sheep: Influence of ultraviolet $B$ radiation on bone metabolism and calcium homeostasis
}

\author{
M. V. Nemeth, ${ }^{*} \dagger$ M. R. Wilkens, $\ddagger$ and A. Liesegang ${ }^{*}+\S^{1}$ \\ *Institute of Animal Nutrition, and \\ †Centre for Clinical Studies, Vetsuisse-Faculty, University of Zurich, CH-8057 Zurich, Switzerland \\ ‡Department of Physiology, University of Veterinary Medicine Hannover, Foundation, DE-30559 Hannover, Germany \\ $\S$ Center for Applied Biotechnology and Molecular Medicine, University of Zurich, CH-8057 Zurich, Switzerland
}

\begin{abstract}
The aim of this study was to investigate how controlled UVB irradiation in combination with reduced nutritional vitamin D (vitD) supply affects vitD status and Ca metabolism of growing goats and sheep. The hypothesis was that, like dairy cows, goats and sheep are able to compensate for the missing nutritional supply of vitD through endogenous production in the skin, with the consequence of a high vitD status and a balanced Ca homeostasis. Sixteen lambs and 14 goat kids aged 3 and a half months were housed in an UVB free environment and fed hay and a vitD-free concentrate over a period of $13 \mathrm{wk}$. One group of each species was exposed to UVB lamps daily during individual feeding; the other groups served as controls. Serum, urine, and feces samples were taken at the start and at a monthly interval. Serum was analyzed for vitD metabolites, bone markers, growth hormone, insulin-like growth factor I, $\mathrm{Ca}$, and P. Apparent digestibility and urinary excretion of $\mathrm{Ca}$ and $\mathrm{P}$ were determined. The left metatarsus was analyzed by peripheral quantitative computer tomography for bone mineral density before starting and at the end of the trial. In wk 13, all animals were slaughtered and samples of skin, rumen, duodenum, kidney, and bone (metatarsus) were collected. Content of sterols of vitD synthesis in the skin, Ca flux rates in rumen and duodenum, expression of vitD receptor in duodenum and kidney, renal and intestinal gene expression of $\mathrm{Ca}$ transport proteins, and renal enzymes related to vitD metabolism were determined. The UVB exposure led to lower 7-dehydrocholesterol content in the skin and a better vitD status (higher serum 25-hydroxyvitamin D), but no signs of vitD deficiency were seen in the control groups and no effect of irradiation was detected in the analyzed parameters of Ca homeostasis. Differences between the 2 species were detected: lambs had
\end{abstract}

Received April 21, 2017.

Accepted July 4, 2017.

${ }^{1}$ Corresponding author: aliese@nutrivet.uzh.ch a higher increase of bone mineral density, lower values of bone markers, growth hormone, and insulin-like growth factor I in serum and higher tachysterol and lower lumisterol content in skin compared with goat kids. The results indicated that growing lambs and goat kids are able to compensate for a vitD-reduced diet by cutaneous vitD synthesis when exposed to UVB irradiation and therefore to keep a high vitD status. In contrast, when a reduced vitD diet is combined with missing UVB exposure, the vitD status drops, but the experimental time was probably too short to induce a vitD deficiency or an effect on Ca homeostasis.

Key words: bone metabolism, calcium, skin, vitamin D

\section{INTRODUCTION}

Endogenous synthesis of vitamin D (vitD) in the skin or nutritional supply is needed to meet vitD requirements of humans and animals. In human skin, when UV radiation (UVB, wavelengths $290-315 \mathrm{~nm}$ ) is absorbed, 7-dehydrocholesterol (7DHC) is photoisomerized to pre-vitamin $\mathrm{D}_{3}$ (pre-D3). This unstable product can be thermally isomerized to vitamin $\mathrm{D}_{3}$ (vitD3, cholecalciferol) or reversibly photoisomerized to the inactive storage forms lumisterol and tachysterol (MacLaughlin et al., 1982; Webb and Holick, 1988; Holick, 2004). Afterward, vitD3 is transferred into the blood circulation and transported by vitD binding protein to the liver where, together with the vitamin $\mathrm{D}_{2}$ (vitD2, ergocalciferol) coming from nutrition, the enzyme vitamin-D-25-hydroxylase (25-OHase) transforms them into 25-hydroxyvitamin D (25vitD; Haddad et al., 1993; Holick, 2008; Jones, 2013). The 25vitD can be stored in tissues as well as transported to the kidney where it is converted to the active product 1,25-dihydroxyvitamin D (1,25vitD, calcitriol) by the enzyme

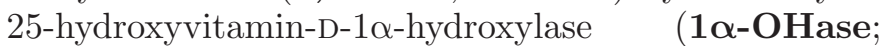
Horst and Reinhardt, 1983; Holick, 2008; Dittmer and Thompson, 2011). The amount of 1,25vitD is controlled by its strictly regulated production by $1 \alpha$-OHase and 
by the degradation through the enzyme 24-hydroxylase (24-OHase; Horst and Reinhardt, 1983; Holick, 2008). High $\mathrm{Ca}$ and $\mathrm{P}$ serum levels decrease serum 1,25vitD, whereas parathyroid hormone, which is secreted when Ca serum level is low, as well as growth hormone $(\mathbf{G H})$ and IGF-I, increase 1,25vitD in serum. (Horst and Reinhardt, 1983; Nesbitt and Drezner, 1993; Tryfonidou et al., 2003; Dittmer and Thompson, 2011).

In ruminants, with sufficient dietary Ca supply, vitD stimulates bone formation and mineralization, whereas if $\mathrm{Ca}$ serum level drops, vitD enhances mobilization from the bones and intestinal Ca absorption (Liesegang and Risteli, 2005; Schröder and Breves, 2006; Dittmer and Thompson, 2011).

It could be demonstrated that humans as well as several different species (including cows) are able to produce vitD in their skin (Holick et al., 1979; Hymøller and Jensen, 2010), in contrast to other species like cats and dogs who depend entirely on dietary supply (How et al., 1994; Morris, 1999). With the experiment of Kovács et al. (2015), it could be demonstrated that goats and sheep are able to produce vitD within their skin, but its importance compared with nutritional supply is still unclear and available data are conflicting (Hidiroglou and Karpinski, 1989; Kohler et al., 2013).

A continuous effort has been made to optimize the dairy production and composition of animal sources for human nutrition, for example, the increase of vitD content in milk (Kohler et al., 2013; Jakobsen et al., 2015; Weiss et al., 2015). The actual need for the common use of diets highly supplemented with vitD in ruminant nutrition needs to be questioned. Indeed, if it can be proven that ruminants are capable of covering their vitD demand by endogenous production through UVB exposure, even in the situation of challenged $\mathrm{Ca}$

Table 1. Food composition

\begin{tabular}{lcc}
\hline Item & Hay & Concentrate \\
\hline DM (\%) & 93.6 & 91.9 \\
Crude fiber (\% of DM) & 21.8 & 6.46 \\
CP (\% of DM) & 13.5 & 12.1 \\
Crude fat (\% of DM) & 2.09 & 3.73 \\
ADF (\% of DM) & 28.4 & 10.3 \\
ADL (\% of DM) & 3.74 & 1.99 \\
NDF (\% of DM) & 50.2 & 30.2 \\
Crude ash (\% of DM) & 8.22 & 6.72 \\
HCl insoluble ash $(\%$ of DM) & 1.43 & 0.58 \\
Ca (g/kg of OM) & 8.93 & 12.3 \\
P (g/kg of OM) & 2.66 & 3.9 \\
Mg (g/kg of OM) & 2.73 & 3.26 \\
Vitamin A $(\mathrm{IU} / \mathrm{kg})$ & - & 24,000 \\
Vitamin D $(\mathrm{IU} / \mathrm{kg})$ & - & 0 \\
\hline
\end{tabular}

${ }^{1}$ Amount of additives according to the manufacturer's declaration (KLIBA NAFAG, Kaiseraugst, Switzerland). homeostasis because of the growing process, livestock husbandry can be optimized.

The aim of our study was to investigate, based on the results of Kovács et al. (2015), how controlled UVB irradiation in combination with reduced nutritional vitD supply affects the vitD status and $\mathrm{Ca}$ regulation (including intestinal Ca absorption, renal excretion, and bone metabolism) of healthy growing goats and sheep of dairy breeds with special attention on speciesspecific differences. Our hypothesis was that they are able to fully compensate the missing nutritional vitD supply through endogenous production in the skin while exposed to UV light. This will lead to a vitD status comparable to a status when vitD is supplemented, and consequently to a well-balanced $\mathrm{Ca}$ homeostasis and healthy growing process.

\section{MATERIALS AND METHODS}

Sixteen East Friesian milk sheep lambs (8 females and 8 males) and 14 Saanen dairy goat kids (all males) were included in this study. At the beginning (wk 0), the mean age was 3 and a half months and the mean BW was $20.8 \pm 0.7 \mathrm{~kg}$. All lambs were shorn before starting the experiment.

Over the trial time of $13 \mathrm{wk}$, the animals were housed in groups, in pens, on wood shavings, in a UVB-free environment. At the end, wk 13, all animals were slaughtered.

Animals were fed individually twice a day with hay of the second cut (at the beginning for growing, stage 3 ) and a concentrate specially designed for these trials without vitD (Food 2921 without vitamin D addition, Kliba Nafag, Kaiseraugst, Switzerland, Table 1). They had access to $\mathrm{NaCl}$ licking bowl [UFA Salzleckstein, sodium chloride (38.5\% sodium) and iodine (100 mg/ $\mathrm{kg}$ ), UFA AG, Herzogenbuchsee, Switzerland] and water ad libitum. Weighing was performed every week and the feed ration was individually adapted. The ration started at daily $700 \mathrm{~g}$ of hay and $250 \mathrm{~g}$ of concentrate for lambs with $20 \mathrm{~kg}$ of BW and $600 \mathrm{~g}$ of hay and $200 \mathrm{~g}$ of concentrate for goat kids with $20 \mathrm{~kg}$ of BW, and was increased continuously until daily $900 \mathrm{~g}$ of hay and 450 $\mathrm{g}$ of concentrate for lambs and $750 \mathrm{~g}$ of hay and $375 \mathrm{~g}$ of concentrate for goat kids, respectively, when reaching $35 \mathrm{~kg}$ of BW. To evaluate the intake of each animal, refusals were weighed 60 min after feeding. All nutrient requirements were covered except for vitD (Agroscope, 2013).

The lambs and goat kids were randomly assigned to 2 groups for each species, after balancing for sex and weight. Half of the animals, UVB-exposed lambs (LUV) and UVB-exposed goat kids (GUV), were ex- 
posed daily to UVB irradiation of UV lamps (Osram Ultra Vitalux, 300 Watt, Osram GmbH, München, Germany) for 30 min during feeding. Irradiation was monitored each morning on the animals' back with a UVB-Radiometer (Solarmeter 6.2, Solartech, Glenside, $\mathrm{PN}$; response range of $280-320 \mathrm{~nm}$ ) to ensure a minimum irradiation of $20 \mu \mathrm{W} / \mathrm{cm}^{2}$. With this dosage, the $30 \mathrm{~min}$ of lamps irradiation corresponded to $55 \mathrm{~min}$ of sun exposure in summer near Zürich (calculated with the mean daily UVB dose measurements of Kohler et al., 2013). The rest of the animals served as controls and were assigned to the lamb control $(\mathbf{L C})$ and goat kid control (GC) groups.

All the procedures in this experiment were approved by the respective Swiss authority for animal welfare (approval number 162/2012, Kantonales Veterinäramt Zürich, Switzerland) in accordance with the animal welfare law of Switzerland.

\section{Sample Collection}

Samples of urine, blood, and feces were collected before the start of the experiment (wk 0), and afterward in wk 3, 7, and 11. Spontaneous morning urine was collected on the sampling day before feeding and immediately cooled at $5^{\circ} \mathrm{C}$. Before the samples were stored at $-20^{\circ} \mathrm{C}, \mathrm{pH}$ was measured $(827 \mathrm{pH}$ Lab, Metrohm AG, Herisau, Switzerland). Venal blood was taken from a jugular vein (Greiner Bio-One Vacuette Z Serum Clot Activator, $5 \mathrm{~mL}$, St. Gallen, Switzerland) 2 and $6 \mathrm{~h}$ after morning feeding or feeding with irradiation and was centrifuged $(3,000 \times g, 15 \mathrm{~min}$, room temperature $)$ within 30 min after sampling. Serum was then stored at -20 and $-80^{\circ} \mathrm{C}$. Feces samples were collected directly from the anus, pooled over 1 wk per animal, and also stored at $-20^{\circ} \mathrm{C}$.

Finally after slaughtering different samples were taken. Within $10 \mathrm{~min}$, samples of the rumen (ventral ruminal sac) and duodenum (directly after pancreatic duct entrance) were taken to perform modified Ussing chamber technique as described by Sidler-Lauff et al. (2010). The net Ca ion fluxes (Jnet) were calculated from the mean detected unidirectional fluxes (Jms fluxes from mucosal to serosal side of the epithelium, Jsm fluxes from serosal to mucosal) with the formula Jnet $=\mathrm{Jms}-\mathrm{Jsm}\left(\mathrm{nmol} / \mathrm{h}\right.$ per $\left.\mathrm{cm}^{2}\right)$. Additionally, mucosa samples from duodenum as well as kidney (cross-section) samples were collected as described in Kovács et al. (2015) and stored at $-80^{\circ} \mathrm{C}$.

Skin samples of 5 different localizations (forehead, neck, antebrachium, back, and kneefold), shaved in advance, were taken within 5 min after slaughter, frozen in liquid nitrogen, and stored at $-80^{\circ} \mathrm{C}$. The left meta- tarsal bones were cleaned from adherent tissues and stored at $-20^{\circ} \mathrm{C}$. Additionally, random food samples of hay and concentrate were taken during the experiment, pooled over time, and analyzed.

\section{Serum and Urine Sample Analyses}

Serum levels of following parameters were analyzed in samples taken $2 \mathrm{~h}$ after morning feeding or feeding with irradiation using commercial kits as described by Kovács et al. (2015): 25vitD (25-hydroxyvitamin D RIA, Immunodiagnostics Systems GmbH, Frankfurt am Main, Germany; intra- and interassay coefficients of variation 5.3 and $8.1 \%$, respectively sensitivity $<3 \mathrm{nmol} / \mathrm{L}$; cross reactivity with 25-hydroxyvitamin $\mathrm{D}_{3}$ and 24,25-dihydroxyvitamin $\mathrm{D}_{3} 100 \%$, with 25-hydroxyvitamin $\mathrm{D}_{2}$ $75 \%$, with vitD3 $<0.01 \%$, and with vitD2 $<0.3 \%$ ), 1,25vitD (1,25-Dihydroxy VitD RIA, Immunodiagnostics Systems GmbH; intra- and interassay coefficients of variation 9.1 and $9.6 \%$, respectively, sensitivity $<8$ $\mathrm{pmol} / \mathrm{L}$; cross reactivity with 1,25-dihydroxyvitamin $\mathrm{D}_{3} 100 \%$, with 1,25-dihydroxyvitamin $\mathrm{D}_{2} 97 \%$, with 24,25-dihydroxyvitamin $\mathrm{D}_{3}$ and 25-hydroxyvitamin $\mathrm{D}_{3}$ $<0.01 \%$ ), GH [sheep somatotropin (GH1) ELISA Kit and goat GH ELISA Kit, LuBioScience GmbH, Lucerne, Switzerland; intra- and interassay coefficients of variation 15 and $15 \%$, respectively, sensitivity $0.675 \mathrm{ng} /$ $\mathrm{mL}$ for sheep and $3.120 \mathrm{ng} / \mathrm{mL}$ for goats], IGF-I (IGF-I ELISA of human IGF-I-IGFBP-blocked, Mediagnost/ TECOmedical AG, Sissach, Switzerland; intra- and interassay coefficients of variation 6.8 and $6.7 \%$, respectively, sensitivity $0.09 \mathrm{ng} / \mathrm{mL}$ ), serum crosslaps (SCL, Serum CrossLaps ELISA, Immunodiagnostic Systems $\mathrm{GmbH}$; intra- and interassay coefficients of variation 1.7 and $2.5 \%$, respectively, sensitivity $0.020 \mathrm{ng} / \mathrm{mL}$ ), and osteocalcin (OC, MikroVue Osteocalcin EIA Kit; Quidel Corporation, San Diego, CA; intra- and interassay coefficients of variation 4.8 and $4.8 \%$, respectively, sensitivity $0.45 \mathrm{ng} / \mathrm{mL}$ ).

In serum and urine samples, $\mathrm{Ca}$ and $\mathrm{P}$ levels were determined by colorimetry using an autoanalyzer (Cobas Mira Roche-autoanalyzer, F. Hoffman-La Roche Ltd., Basel, Switzerland) and commercial test kits (Ca, test kit DIA00460, Cresolphthalein complexone; P, test kit DIA00620, ammonium molybdate; Diatools AG, Villmergen, Switzerland, intra- and interassay coefficients of variation 0.62 and $1.66 \%$ for Ca, respectively, and 0.86 and $1.07 \%$ for $\mathrm{P}$, respectively, sensitivity 0.050 $\mathrm{mmol} / \mathrm{L}$ for $\mathrm{Ca}$ and $0.065 \mathrm{mmol} / \mathrm{L}$ for $\mathrm{P})$. In serum samples, the mean values of the 2 measurements 2 and $6 \mathrm{~h}$ after morning feeding or feeding with irradiation were calculated. Urine creatinine (Crea) was also analyzed with the same method using another testkit (Crea 
Jaffe, DIA00540; Diatools AG, intra- and interassay coefficients of variation 0.83 and $0.85 \%$, respectively, sensitivity $18 \mu \mathrm{mol} / \mathrm{L}$ ), and the results of $\mathrm{Ca}$ and $\mathrm{P}$ were related to these values.

\section{Quantitative RT-PCR}

In samples of the kidney, mRNA expression of vitD receptor (VDR), calbindin $\mathrm{D}_{28 \mathrm{k}}$ (Calb-D28k), 1 $\alpha$-OHase (CYP27B1), and 24-OHase (CYP24A1) was analyzed. The RNA extraction was performed following the TRI Reagent protocol (TRI Reagent Solution, Ambion, Rotkreuz, Switzerland) and RNA concentration was measured by spectrophotometry using NanoDrop 2000 (Thermo Fisher Scientific, Waltham, MA). The RNA samples were than reverse transcribed in cDNA using a commercial kit (QuantiTect Reverse Transcription Kit, Qiagen, Hilden, Germany), according to the manufacturer's instructions using $1 \mu \mathrm{g}$ of RNA in a reaction volume of $20 \mu \mathrm{L}$.

For quantification of RNA expression of VDR, CalbD28k, CYP27B1, and the housekeeping genes $\beta$-actin (for VDR) and GAPDH (for Calb-D28k, CYP27B1), we used specific primers and probes (Table 2). A reaction mixture $(20 \mu \mathrm{L})$ containing TaqMan Universal PCR Master Mix (Applied Biosystems, Darmstadt, Germany), specific primers $(1 \mu M)$, specific probe $(0.75$ $\mu M$ ), and reverse transcribed RNA (50 ng) was prepared. After the PCR products were amplified $\left(95^{\circ} \mathrm{C}\right.$, $2 \mathrm{~s}, 45$ cycles of $95^{\circ} \mathrm{C}, 3 \mathrm{~s}$ and $60^{\circ} \mathrm{C}, 30 \mathrm{~s}$ ), they were analyzed on a 7500 Fast Real Time PCR System (ABI 7500Fast Sequence Detection System, Life Technologies, Waltham, MA). Cycle threshold values were determined with a threshold of 0.1 .

Expression of CYP24A1 was determined using SYBR Green PCR assays (with a specific primer, Table 2) using a real-time PCR cycler (CFX96TM, Bio-Rad, Munich, Germany) as described by Herm et al. (2015).
Absolute copy numbers were determined using calibration curves generated with cloned PCR fragment standards as described by Wilkens et al. (2009).

Efficiency of the different PCR assays tested in advance for dilutions of intestinal or renal cDNA and cloned standard ranged from 90 to $120 \%$. Specificity of the amplicons was verified using the National Center for Biotechnology Information Blast (http://blast.ncbi .nlm.nih.gov/Blast.cgi). Parallel PCR assays for each gene were performed with cDNA samples, plasmid standards, and a no-template control containing water. Each series of experiments was carried out twice.

\section{Western Blot Analysis}

In samples of the duodenum, VDR expression on the protein level as well as GAPDH as the housekeeping protein were analyzed by Western blot analysis as described by Kovács et al. (2015). The antibodies used for VDR were an antibody against VDR (Abcam AB54387, Sigma-Aldrich Chemie GmbH, Buchs, Switzerland) and a horseradish peroxidase-conjugated polyclonal anti-rat IgG (A9037, Sigma-Aldrich Chemie $\mathrm{GmbH}$ ) and those for GAPDH were monoclonal antiGAPDH (G8795, Sigma-Aldrich Chemie GmbH) and polyclonal anti-mouse IgG-specific peroxidase antibody (A2304, Sigma-Aldrich Chemie GmbH). Signal visualization was performed using enhanced chemiluminescence (Pierce, Thermo Scientific, Bonn, Germany) and a ChemiDoc system (Bio-Rad, München, Germany). For normalization, the ratio of protein expression of VDR to the GAPDH was calculated.

\section{Skin Sample Analysis}

Skin samples were analyzed by HPLC at $254 \mathrm{~nm}$ after being prepared as described by Morris (1999) with small modifications (Kovács et al., 2015). Using a Nu-

Table 2. Primers and probes used for TaqMan (Applied Biosystems, Darmstadt, Germany) assays [vitamin D receptor (VDR), calbindin $\mathrm{D}_{28 \mathrm{k}}$ (Calb-D28k), 1 $\alpha$-hydroxylase (CYP27B1), $\beta$-actin, and GAPDH], synthesized by Mycrosynth AG (Balgach, Switzerland), and for SYBR Green PCR assays (24-hydroxylase, CYP24A1, source: Herm et al., 2015), synthesized by TIB Molbiol (Berlin, Germany)

\begin{tabular}{|c|c|c|}
\hline Gene & Sense and antisense primers $\left(5^{\prime} \rightarrow 3^{\prime}\right)$ & Probe \\
\hline Calb-D28k & $\begin{array}{l}\text { CAGAATCCCACCTGCAATCA } \\
\text { TCAAGTTCTGAAGCTCCTTTC }\end{array}$ & FAM-CTGGCTTCATTTCGACGCTGA-BHQ-1 \\
\hline$C Y P_{27 B 1}$ & $\begin{array}{l}\text { CACTGGTCACTCTGTGTCACT } \\
\text { CGCTTGCCAAAGCCAAAGG }\end{array}$ & FAM-ACTTCAAGGGACCCTGCCCA-BHQ-1 \\
\hline$\beta$-Actin & $\begin{array}{l}\text { ACTGGGACGACATGGAGAAG } \\
\text { GTCATCTTCTCACGGTTGGC }\end{array}$ & FAM-CACCTTCTACAACGAGCTGC-BHQ-1 \\
\hline
\end{tabular}


cleosil silica column (EC250/4.6 Nucleosil 100-5C18, Macherey-Nagel, Düren, Germany), 7DHC, pre-D3, lumisterol, tachysterol, and vitD3 were determined.

\section{Peripheral Quantitative Computed Tomography}

Peripheral quantitative computed tomography (pQCT; XCT 960 A Knochen Scanner; Stratec Medizinaltechnik, Pforzheim, Germany) of the left metatarsus was performed before starting the experiment (wk 0 ) and after slaughter (wk 13). The length of the metatarsus was measured, and total, cortical, and trabecular bone mineral density (BMD) as well as cortical bone thickness (CBT) were determined (cortical mode 2, threshold for cortical bone $>640 \mathrm{mg} / \mathrm{cm}^{3}$ ) distal in the metaphysis ( $10 \%$ of the metatarsus lengths) and in the middle of the diaphysis (50\% of the metatarsus lengths) as described by Liesegang and Risteli (2005).

\section{Feed and Feces Analysis}

The DM content of feed and feces (\%) was determined by drying of 3 to $5 \mathrm{~g}$ feed samples and 3 to $5 \mathrm{~g}$ pooled feces samples at $103^{\circ} \mathrm{C}$ up to weight constancy. Afterward, samples were ashed at $550^{\circ} \mathrm{C}$ in a muffle furnace, hydrolyzed in hydrochloric acid $0.8 \%$, and analyzed for content of $\mathrm{Ca}$ and $\mathrm{P}$ by colorimetry using the same test kits and autoanalyzer as for urine and serum samples. The amount of crude ash, $\mathrm{HCl}$ insoluble ash, crude fat, $\mathrm{CP}$, and crude fiber in feed was determined by proximate analysis. The ADL and ADF in feed and feces, as well as the NDF in feed, were analyzed as described by Van Soest et al. (1991).

Apparent digestibility (AD) of $\mathrm{Ca}$ and $\mathrm{P}$ were calculated by the indicator method using ADL as the indicator and the formula by Stangl (2014):

$\mathrm{AD}(\%)=100-\frac{\% \text { indicator in feed }}{\% \text { indicator in feces }} \times \frac{\% \text { mineral in feces }}{\% \text { mineral in feed }} \times 100$.

\section{Statistical Analysis}

The experimental design was a 2-factorial design with the factors irradiation (UV or $\mathrm{C}$ ) and species ( $\mathrm{L}$ or G) that built the 4 groups LUV, LC, GUV, and GC.

The statistical analyses were performed with SYSTAT (Version 13 for Windows, Systat Software Inc., San Jose, CA). To test the differences between the time-dependent patterns (for blood and urine samples, apparent digestibility, bone densities, and BW) and between the localization-dependent patterns (skin samples) in the groups, a multivariate ANOVA for repeated measurements (MANOVA) was performed, after testing the data for normal distribution by Shapiro-Wilk test. If the data were not normally distributed, results were verified by nonparametric tests: Kruskal-Wallis was used to investigate the difference between the groups, and a Wilcoxon signed-rank test for paired samples was used to compare the time dependent effect within each group. To exclude a possible influence of the sex on the irradiation treatment within the lambs, a 2-way ANOVA (sex, irradiation, and sex $\times$ irradiation) was performed for all analyzed parameters. No interaction between irradiation and sex was found in any of the investigated parameters.

Additionally, Pearson's correlation coefficient between serum 25vitD levels and sterol contents in the skin was calculated and significance was evaluated by $t$-test (zero correlation).

All data are reported as means \pm standard error. Differences were considered significant at $P<0.05$ for all tests.

\section{RESULTS}

\section{$B W$}

Body weight increased gradually, indicating normal growth, in lambs from $21.2 \pm 0.58 \mathrm{~kg}$ in wk 0 to $34.2 \pm$ $0.85 \mathrm{~kg}$ in wk 13, and in goat kids from $20.2 \pm 1.25 \mathrm{~kg}$ in wk 0 to $29.7 \pm 1.53 \mathrm{~kg}$ in wk 13 . The mean weekly increase was higher $(P<0.001)$ in lambs $(0.996 \pm 0.032$ $\mathrm{kg} / \mathrm{wk})$ compared with goat kids $(0.748 \pm 0.036 \mathrm{~kg} /$ wk), but we observed no influence of the irradiation on the mean weekly increase and no significant difference in the BW between the groups at any time point.

\section{Skin}

Concentration of 7DHC in skin was influenced by irradiation (Table 3). In lambs, 7DHC values were significantly lower in LUV than in LC in skin samples from the back $(P=0.013)$ and the neck $(P=0.027)$, whereas in goat kids it was lower in GUV than in GC in samples from the back $(P=0.012)$, neck $(P=$ $0.003)$, and antebrachium $(P=0.001)$. In both species, the lowest concentrations overall were discovered in samples of the back, followed by the neck, and the highest were in the skin of the forehead $(P<0.001)$. The 7DHC concentration of the back and the neck correlated negatively with the $25 \mathrm{vitD}$ serum concentration in wk $11(\mathrm{r}=-0.547, P=0.012$ and $\mathrm{r}=-0.461, P$ $=0.004$, respectively; Figure 1). No species difference could be detected.

The concentration of pre-D3 in the skin was not influenced by irradiation, species, or localization. 


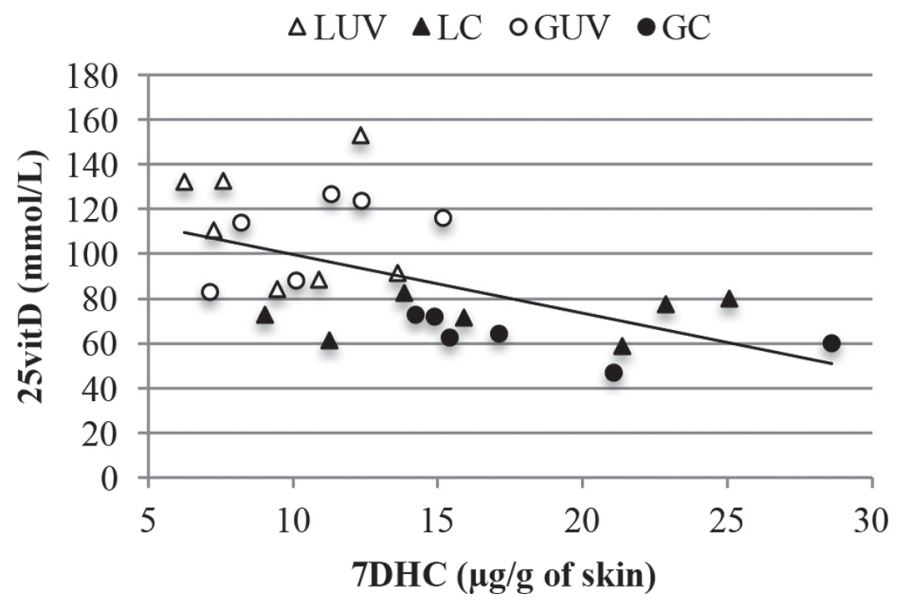

Figure 1. Correlation between 25-hydroxyvitamin D (25vitD) in serum (wk 11) and 7-dehydrocholesterol (7DHC) in the back skin of lambs and goat kids. LUV = UVB-exposed lambs; LC = lambs control; GUV = UVB-exposed goat kids; $\mathrm{GC}=$ goat kids control. Pearson $\mathrm{r}=-0.547, P=0.012$.
Vitamin $\mathrm{D}_{3}$ could not always be detected in each skin sample of the different locations in lambs or in the samples of forehead of goat kids, whereas in samples of all other localizations of the goat kids, vitD3 was detectable. Again, no influence of irradiation, species, or location was found.

We observed a species difference in concentrations of tachysterol and lumisterol in the skin. Lumisterol was generally lower in lambs than in goats kids (significant only in samples of the back and the kneefold, with $P$ $=0.002$ and $P=0.010$, respectively), and again was not detected in all lamb samples. On the other hand, tachysterol was generally lower in goats kids than in lambs (significant in samples of the head, antebrachium, and kneefold with $P=0.004, P=0.004$, and $P$ $<0.001$, respectively) and was not always detected in goat kid samples. An irradiation effect was not detected for tachysterol or lumisterol.

Table 3. Effect of irradiation on mean $( \pm \mathrm{SE})$ content of sterols in skin of lambs and goat kids after slaughter ( $\mu \mathrm{g} / \mathrm{g}$ of skin)

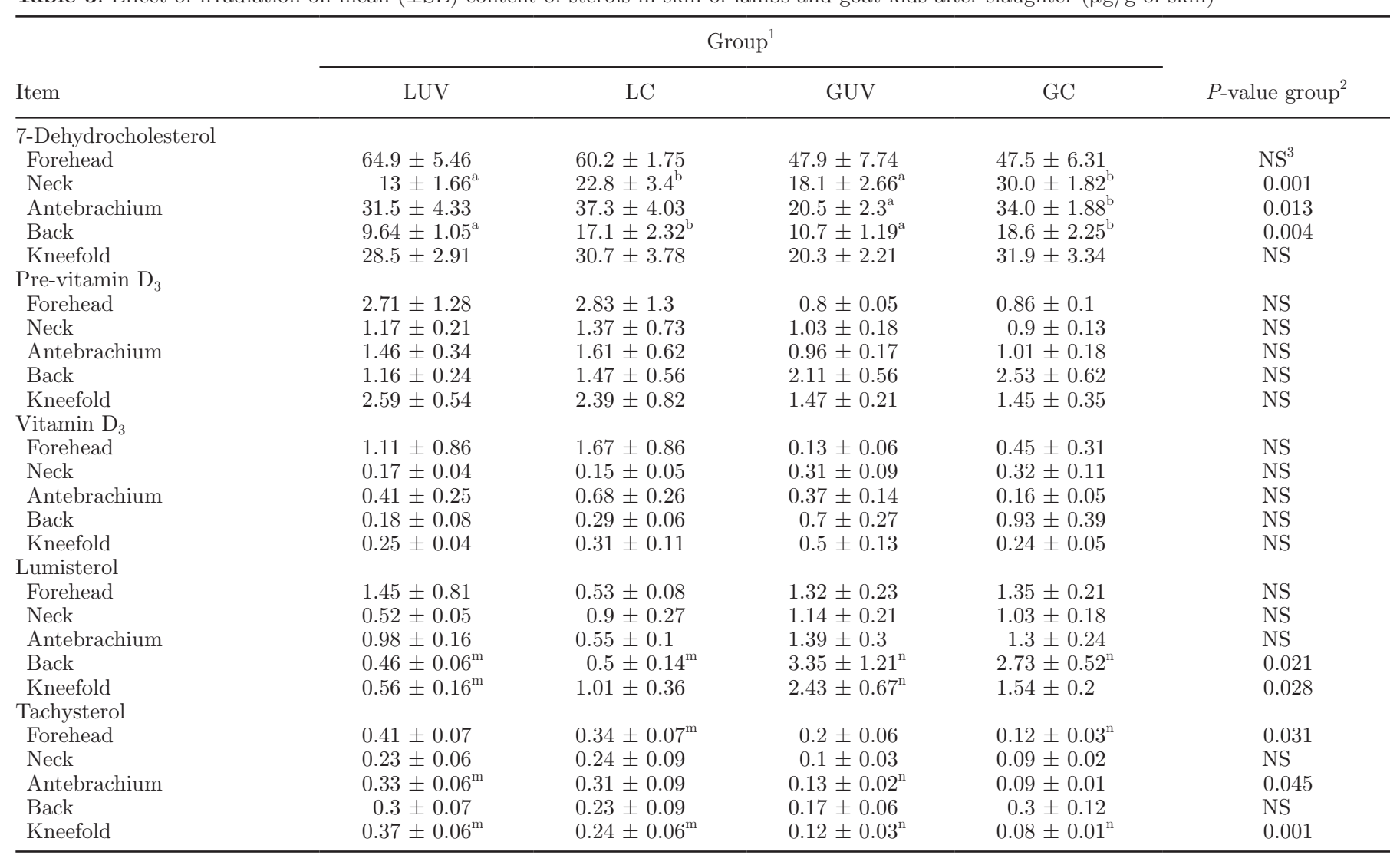

\footnotetext{
${ }^{\mathrm{a}, \mathrm{b}}$ Different superscripts within a row and the same species indicate a significant influence by irradiation treatment $(P<0.05)$.

${ }^{\mathrm{m}, \mathrm{n}}$ Different superscripts within a row indicate a significant influence by species $(P<0.05)$.

${ }^{1} \mathrm{LUV}=\mathrm{UVB}$-exposed lambs; $\mathrm{LC}=$ lambs control; GUV = UVB-exposed goat kids; GC = goat kids control.

${ }^{2}$ Differences in groups reflect both differences between species as well as irradiation treatment.

${ }^{3}$ NS: $P>0.05$.
} 


\section{Serum}

Serum 25vitD levels were significantly higher in LUV than LC over the whole experiment (Table 4). In goat kids the difference of GUV having higher levels than GC was significant from wk 3 until the end of the experiment. Only in wk 0 was there a species-specific difference, with goat kids having higher 25vitD levels compared with lambs. Over time, serum 25vitD levels increased significantly in the first $3 \mathrm{wk}$ in lambs $(P=$ 0.012 for LUV and $P=0.017$ for LC), and decreased significantly in both control groups from wk 3 to 11
(LC, $P=0.012$; and GC, $P=0.018$ ), whereas in irradiated groups they remained higher with fluctuations.

Serum 1,25vitD levels decreased significantly over time only in the control groups (Table 4), in LC from wk 0 to $7(P=0.036)$, and in $\mathrm{GC}$ from wk 0 to 11 ( $P$ $=0.018)$. This decrease was not enough to create a significant difference between the groups at any time point.

In addition, no irradiation-dependent effect was detected in serum for the analyzed minerals $(\mathrm{Ca}, \mathrm{P})$, bone parameters (OC, SCL), and IGF-I. Serum Ca levels were higher $(P<0.001)$ in lambs (range $2.47-3.46$

Table 4. Effect of irradiation on mean $( \pm \mathrm{SE})$ serum levels of 25-hydroxyvitamin D (25vitD), 1,25-dihydroxyvitamin D (1,25vitD), serum crosslaps (SCL), osteocalcin (OC), growth hormone (GH), and IGF-I in lambs and goat kids

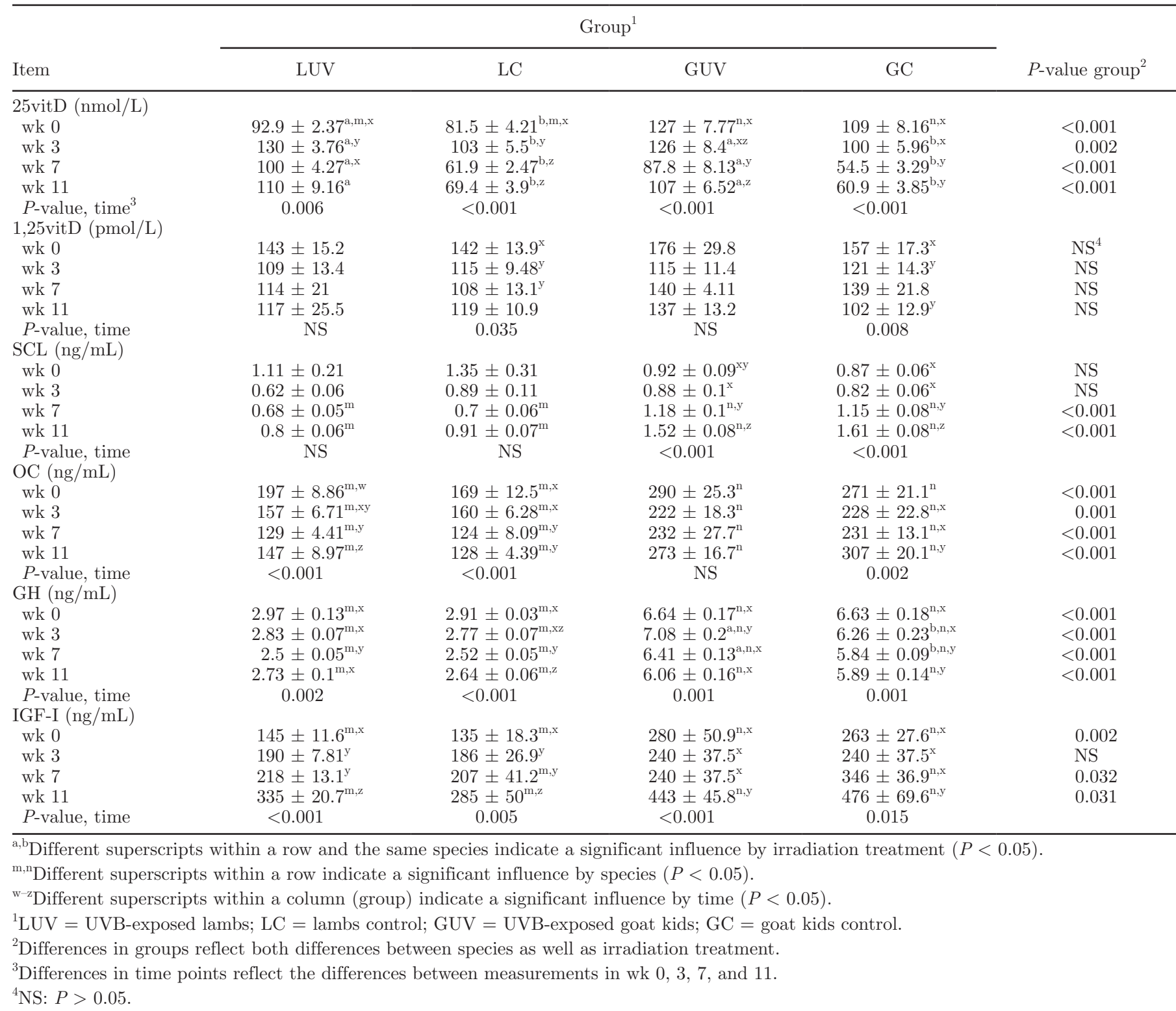


$\mathrm{mmol} / \mathrm{L}$ ) than in goat kids (range $2.28-2.82 \mathrm{mmol} / \mathrm{L}$ ) during the entire experiment. No time-dependent effect was detected. Serum P level of goat kids increased over time with a significant increase from wk 7 to $11(P=$ 0.003 ), whereas in lambs it did not vary significantly. At the last sampling in wk 11, goat kids had significant higher levels of serum $\mathrm{P}$ levels than lambs $(P<0.001)$. The range during the whole experiment was 1.47 to 2.49 $\mathrm{mmol} / \mathrm{L}$ for lambs and 1.49 to $2.65 \mathrm{mmol} / \mathrm{L}$ for goat kids. Serum OC levels (Table 4) in lambs decreased significantly over time $(P=0.001)$ and were lower than in goat kids over the whole experiment $(P<0.001)$. Also, SCL levels (Table 4) were lower in lambs than in goat kids through the second half of the experiment (wk 7 and 11, $P<0.001$ ) because of a time-dependent increase from wk 0 to 11 in goat kids $(P=0.001)$. Serum IGF-I levels increased significantly from wk 0 to 11 in all groups (lambs, $P=0.012 ; \mathrm{LC}, P=0.012$; GUV, $=0.018$; and GC, $P=0.018$, Table 4). Over the whole time, goat kids had higher serum levels than lambs, but it reached statistical significance only in wk 0,7 , and 11 ( $P<0.001, P=0.025$, and $P=0.005$, respectively).

Also, values of serum GH were always significantly higher in goat kids than in lambs $(P<0.001$, Table 4$)$, but showed different time courses. Whereas in lambs and GC the significant decrease until wk $7(P<0.001$ and $P=0.028$, respectively) was followed by an increase until wk 11 (significant only in lambs, $P=0.002$ ), in GUV a peak occurred in wk $3(P=0.028)$ followed by a decrease until wk $11(P=0.028)$. Consequently, we saw an irradiation effect in wk 3 and $7(P=0.021$ and $P=$ 0.003 , respectively), where GC had significantly lower GH levels in serum than GUV.

\section{Urine}

Urinary $\mathrm{Ca}$ and $\mathrm{P}$ content was not influenced by irradiation. Over time, values of $\mathrm{Ca} / \mathrm{Crea}$ content in lambs increased from $0.051 \pm 0.007 \mathrm{mmol} / \mathrm{mmol}$ of Crea in wk 0 to $0.153 \pm 0.020 \mathrm{mmol} / \mathrm{mmol}$ of Crea in wk 11 $(P<0.001)$, whereas in goat kids it increased from $0.178 \pm 0.028 \mathrm{mmol} / \mathrm{mmol}$ of Crea in wk 0 until 0.389 $\pm 0.076 \mathrm{mmol} / \mathrm{mmol}$ of Crea in wk $3(P=0.013)$ and decreased again till $0.117 \pm 0.017 \mathrm{mmol} / \mathrm{mmol}$ of Crea in wk $11(P=0.005)$. Consequently, goat kid $\mathrm{Ca} / \mathrm{Crea}$ content in urine was higher in wk 0 and 3 and lower in wk 7 compared with lambs $(P<0.001, P=0.001$, and $P=0.001$, respectively). The content of $\mathrm{P} /$ Crea in urine did not vary significantly over time in any of the groups (from $0.097 \pm 0.004 \mathrm{mmol} / \mathrm{mmol}$ of Crea in wk 0 to $0.111 \pm 0.015 \mathrm{mmol} / \mathrm{mmol}$ of Crea in wk 11), but in wk 11 we found lower levels in goat kids than in lambs $(P=0.011,0.071 \pm 0.008$, and $0.144 \pm 0.024$ $\mathrm{mmol} / \mathrm{mmol}$ of Crea, respectively).

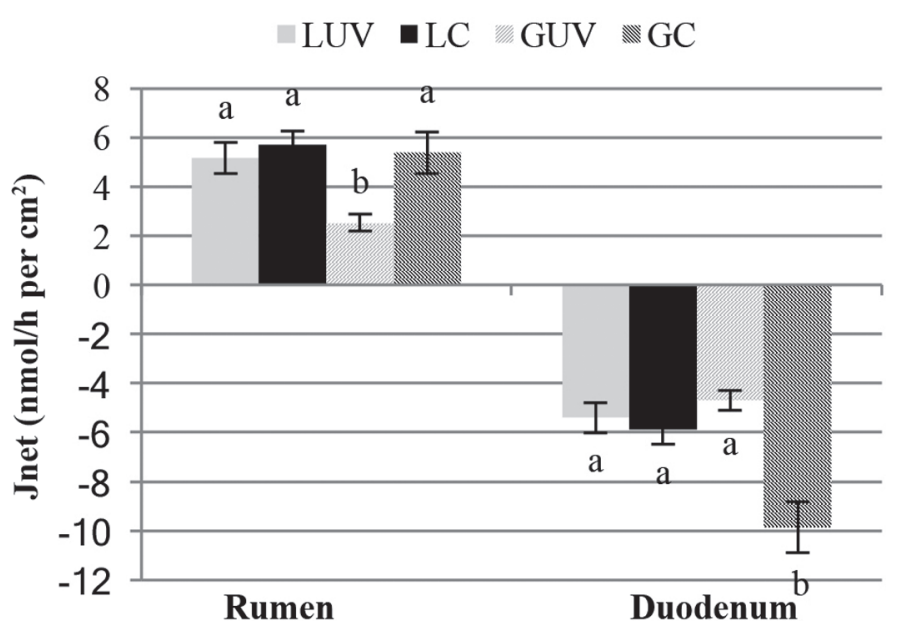

Figure 2. Results of Ussing chamber technique: net Ca ion fluxes (Jnet) through rumenal and duodenal mucosa of goat kids and lambs. Calculated from the mean detected unidirectional fluxes (Jms fluxes from the mucosal to serosal side of the epithelium, and Jsm fluxes from serosal to mucosal) with the formula: Jnet $=\mathrm{Jms}-\mathrm{Jsm}(\mathrm{nmol} / \mathrm{h}$ per $\left.\mathrm{cm}^{2}\right) . \mathrm{LUV}=\mathrm{UVB}$-exposed lambs; $\mathrm{LC}=$ lambs control; GUV $=$ UVBexposed goat kids; $\mathrm{GC}=$ goat kids control. Groups within 1 location with different letters differ significantly $(P<0.050)$. Mean $\pm \mathrm{SE}$.

\section{Ussing Chamber}

We observed a net active Ca absorption in rumen and a net active Ca secretion in duodenum (Figure 2). In goat kids, a significant irradiation-dependent difference was found: the absorption in rumen as well as the secretion in duodenum $(P=0.009$ and $P=0.001$, respectively) was lower in GUV than in GC. A speciesspecific effect was detected in both localizations, in rumen with GUV lower than LUV $(P=0.004)$ and in duodenum with GC higher $(P=0.004)$ than LC.

\section{Feces}

In feces samples, we did not observe either an irradiation-dependent effect or a time effect for $\mathrm{AD}$ of $\mathrm{Ca}$ and $\mathrm{P}$ (Table 5). The species difference showed higher AD of $\mathrm{Ca}$ in goat kids than in lambs in wk $3(P=0.006)$ and $7(P<0.001)$, and a higher $\mathrm{AD}$ of $\mathrm{P}$ in lambs than in goat kids at those time points $(P<0.001$ and $P=$ 0.001, respectively).

\section{PCR/WB}

In the kidneys, expression of VDR, Calb-D28k, $1 \alpha-O H a s e$, and 24-OHase on RNA level was compared within 1 species in relation to the respective control group. No irradiation-dependent effect was found (Table 6). Expression on protein level of VDR in duodenum within 1 species was not influenced by irradiation (Table 6). 
Table 5. Effect of irradiation on mean $( \pm \mathrm{SE})$ apparent digestibility of $\mathrm{Ca}$ and $\mathrm{P}$ calculated with ADL used as an indicator, in lambs and goat kids

\begin{tabular}{lccccc}
\hline & \multicolumn{4}{c}{ Group $^{1}$} & \\
\cline { 2 - 4 } Item & LUV & LC & GUV & GC & $P$-value group ${ }^{2}$ \\
\hline Ca (\%) & & & \\
wk 3 & $18.4 \pm 2.53^{\mathrm{m}}$ & $25.7 \pm 3.21$ & $29.9 \pm 2.39^{\mathrm{n}}$ & $35.1 \pm 2.98$ & 0.002 \\
wk 7 & $20.6 \pm 3.5^{\mathrm{m}}$ & $23.3 \pm 4.34^{\mathrm{m}}$ & $38 \pm 2.62^{\mathrm{n}}$ & $37.1 \pm 3.41^{\mathrm{n}}$ & 0.002 \\
wk 11 & $24.4 \pm 2.7$ & $26.1 \pm 6.78$ & $32.6 \pm 3.46$ & $37.6 \pm 3.2$ & NS $^{3}$ \\
$P$-value, time & $\mathrm{NS}$ & $\mathrm{NS}$ & $\mathrm{NS}$ & $\mathrm{NS}$ & \\
P (\%) & & & & \\
wk 3 & $9.76 \pm 3.73^{\mathrm{m}}$ & $10.67 \pm 3.47^{\mathrm{m}}$ & $12.76 \pm 6.46^{\mathrm{n}}$ & $-4.58 \pm 4.68^{\mathrm{n}}$ & 0.003 \\
wk 7 & $9.61 \pm 3.02^{\mathrm{m}}$ & $14.69 \pm 5.04^{\mathrm{m}}$ & $-4.9 \pm 5.27^{\mathrm{n}}$ & $-3.83 \pm 4.44^{\mathrm{n}}$ & 0.009 \\
wk 11 & $13.94 \pm 3.19$ & $11.15 \pm 5.97$ & $5.44 \pm 7.17$ & $-0.04 \pm 6.17$ & NS \\
$P$-value, time & $\mathrm{NS}$ & $\mathrm{NS}$ & $\mathrm{NS}$ & $\mathrm{NS}$ & \\
\hline
\end{tabular}

${ }_{\mathrm{m}, \mathrm{n}}$ Different superscripts within a row indicate a significant influence by species $(P<0.05)$.

${ }^{1} \mathrm{LUV}=\mathrm{UVB}$-exposed lambs; LC $=$ lambs control; GUV = UVB-exposed goat kids; GC = goat kids control. ${ }^{2}$ Differences in groups reflect both differences between species as well as irradiation treatment.

${ }^{3} \mathrm{NS}: P>0.05$.

${ }^{4}$ Differences in time points reflect the differences between measurements in wk 3, 7, and 11 .

\section{PQCT}

At that the end of the experiment, we found no irradiation-dependent effect on any of parameters measured by pQCT (Table 7). Total BMD (diaphysis and metaphysis) as well as cortical BMD and CBT increased significantly over time in all groups $(P<0.014)$ except in GC where the increase of total BMD and CBT in diaphysis did not reach significance. In the trabecular BMD, the time-dependent effect was not significant.
In the diaphysis we found significantly higher values of cortical and total BMD in lambs compared with goat kids at the end of the experiment $(P<0.001)$. A species-specific difference in the metaphysis was found in wk 0, where the total and trabecular BMD was significantly lower in lambs compared with goat kids $(P<0.022)$. Also, LUV had lower values of total and trabecular BMD in wk 0 compared with LC. These differences in the metaphysis disappeared until the end of the trial.

Table 6. Effect of irradiation on mean ( \pm SE) RNA expression of vitamin D receptor (VDR), calbindin $\mathrm{D}_{28 \mathrm{k}}$

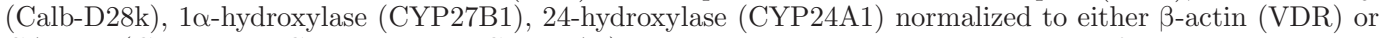
GAPDH (Calb-D28k, CYP27B1, and CYP24A1) in kidneys and on protein expression of VDR normalized to GAPDH in duodenum determined with Western blot in lambs and goat kids

\begin{tabular}{|c|c|c|c|c|c|}
\hline \multirow[b]{2}{*}{ Item } & \multicolumn{4}{|c|}{ Group $^{1}$} & \multirow[b]{2}{*}{$P$-value, group ${ }^{2}$} \\
\hline & LUV & $\mathrm{LC}$ & GUV & GC & \\
\hline \multicolumn{6}{|l|}{ Lambs } \\
\hline \multicolumn{6}{|l|}{ Kidney } \\
\hline VDR & $0.64 \pm 0.17$ & $1 \pm 0.18$ & & & $\mathrm{NS}^{3}$ \\
\hline Calb-D28k & $1.45 \pm 0.77$ & $1 \pm 0.25$ & & & NS \\
\hline CYP27B1 & $0.87 \pm 0.42$ & $1 \pm 0.43$ & & & NS \\
\hline CYP24A1 & $1.85 \pm 0.42$ & $1 \pm 0.16$ & & & NS \\
\hline \multicolumn{6}{|l|}{ Duodenum } \\
\hline VDR & $1.27 \pm 0.13$ & $1 \pm 0.2$ & & & NS \\
\hline \multicolumn{6}{|l|}{ Goat kids } \\
\hline \multicolumn{6}{|l|}{ Kidney } \\
\hline VDR & & & $1.37 \pm 0.23$ & $1 \pm 0.25$ & NS \\
\hline Calb-D28k & & & $1.64 \pm 0.45$ & $1 \pm 0.21$ & NS \\
\hline CYP27B1 & & & $0.76 \pm 0.34$ & $1 \pm 0.34$ & NS \\
\hline CYP24A1 & & & $0.43 \pm 0.15$ & $1 \pm 0.38$ & NS \\
\hline \multicolumn{6}{|l|}{ Duodenum } \\
\hline VDR & & & $1.22 \pm 0.14$ & $1 \pm 0.1$ & NS \\
\hline
\end{tabular}

${ }^{1} \mathrm{LUV}=\mathrm{UVB}$-exposed lambs; LC = lambs control; GUV = UVB-exposed goat kids; GC = goat kids control. ${ }^{2}$ Reflects differences between irradiation treatment within 1 species.

${ }^{3} \mathrm{NS}: P>0.05$. 
Table 7. Effect of irradiation on mean $( \pm \mathrm{SE})$ metatarsal bone mineral density $(\mathrm{BMD})$ and cortical bone thickness $(\mathrm{CBT})$ in lambs and goat kids

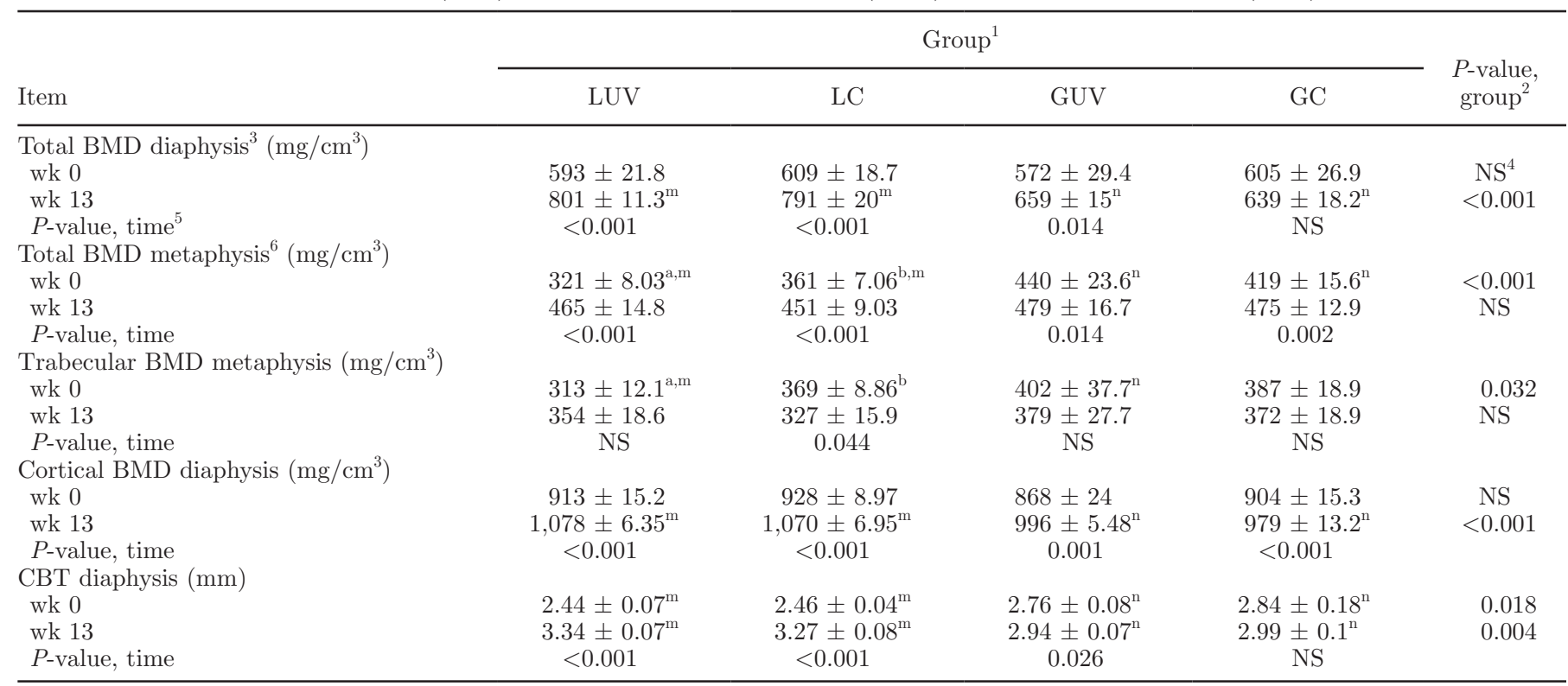

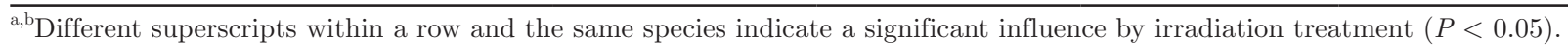

${ }^{\mathrm{m}, \mathrm{n}}$ Different superscripts within a row indicate a significant influence by species $(P<0.05)$.

${ }^{1} \mathrm{LUV}=\mathrm{UVB}$-exposed lambs; $\mathrm{LC}=$ lambs control; GUV = UVB-exposed goat kids; GC = goat kids control.

${ }^{2}$ Differences in groups reflect both differences between species as well as irradiation treatment.

${ }^{3}$ Measuring point at $50 \%$ of metatarsus length.

${ }^{4}$ NS: $P>0.05$.

${ }^{5}$ Differences in time points reflect the differences between measurements in wk 0 and 13 .

${ }^{6}$ Measuring point at $10 \%$ of metatarsus length.

The CBT was significantly higher in wk 0 in goat kids compared with lambs $(P=0.001)$, whereas at the end of the experiment, in wk 13, the situation was the inverse $(P<0.001)$.

\section{DISCUSSION}

\section{Vitamin D Status and Synthesis in the Skin}

In this study, we investigated the hypothesis that growing lambs and goat kids of dairy breeds are able to fully compensate for a reduced vitD content in food by producing vitD within their skin. Level of $25 \mathrm{vitD}$ in serum is recognized to be the most reliable indicator for vitD status (Adams et al., 1982). In the test kit used to determine 25vitD level in serum, no differentiation is present between 25-dihydroxyvitamin $\mathrm{D}_{2}$ (coming from the vitD2 acquired through nutrition), 25-dihydroxyvitamin $\mathrm{D}_{3}$ (coming from endogenous production), and 24,25-dihydroxyvitamin $\mathrm{D}$, and therefore all of these storage forms are included independent of their origin (Horst and Reinhardt, 1983). Both irradiated groups (LUV and GUV) had a better vitD status with higher 25 vitD serum levels compared with the control groups
(LC and GC). In the experiment of Kovács et al. (2015), lambs and goat kids were irradiated in the same way as in the present study, but had a high vitD supply in the diet. The values of $25 \mathrm{vitD}$ at the end of that trial were in a similar range as the values of our irradiated groups (LUV and GUV), whereas the levels of 25vitD of our control groups (LC and GC) without any vitD source were clearly lower. This shows that the irradiation was sufficient to compensate for the lack of vitD and maintain the serum 25vitD levels. Additionally, the drop of the initially high serum 25vitD levels in our control groups confirms that the natural sources of vitD in the feedstuffs in this study were not sufficient to cover the vitD requirements of the animals.

The natural content of vitD in hay depends on composition, season, and climatic conditions of the region as well as drying method. Therefore, there is a high variation in the vitD contents described in the literature. Jäpelt et al. (2011), for example, found levels between 2.8 and $255.6 \mathrm{IU}$ of vitD2 $/ \mathrm{kg}$ of OM (analyzed by liquid chromatography tandem mass spectrometry) in different ryegrass over the seasons in Denmark, whereas Kohler et al. (2013) found a higher level of 2,508 IU of vitD2/ $\mathrm{kg}$ of DM in lowland hay in Switzerland (ana- 
lyzed by HPLC). Considering that the recommended vitD supply, to reach a normal vitD status, is between 120 and $500 \mathrm{IU} / \mathrm{d}$ for sheep, and between 250 and 1500 $\mathrm{IU} / \mathrm{d}$ for goats (Agroscope, 2013), the mean content of vitD in the hay used must have been under $153 \mathrm{IU}$ of vitD/kg of DM. Therefore, the absorbed vitD naturally present in the hay did not cover the vitD requirement of the animals (which explains the dropped vitD levels in the control groups), but still provided a significant vitD amount, which prevented the drop of the vitD levels in a vitD-deficient range.

In most species (including humans), the normal range of $25 v i t D$ in serum is considered to be between 75 and $150 \mathrm{nmol} / \mathrm{L}$, whereas levels between 25 and $75 \mathrm{nmol} / \mathrm{L}$ are defined as vitD insufficiency (meaning that endocrine function such as immune regulation and cell differentiation are compromised), and levels $<25$ $\mathrm{nmol} / \mathrm{L}$ are defined as actual vitD deficiency with negative effects on the classical vitD function (such as bone metabolism and calcium homeostasis investigated in this study; Norman, 2011; Weber et al., 2014; Nelson et al., 2016). Different authors also described lower ranges of 25vitD in lambs and calves (compared with adult animals) with good health and no signs of classical vitD deficiency (Horst and Littledike, 1982; Handel et al., 2016; Nelson et al., 2016).

The animals in this study had a normal initial vitD status thanks to the high vitD intake due to the vitD content in the normal concentrate fed before starting the experiment and the vitD intake via milk before weaning. Indeed, for newborn ruminants, in contrast to other species, milk can be an adequate source of vitD under the condition of a high vitD status in combination with a moderate milk yield of the dam (Kohler et al., 2013; Weiss et al., 2015; Hymøller et al., 2017). The $25 \mathrm{vitD}$ can then be stored in the body tissue (primary fat, muscle, and liver) to help prevent a fast drop of vitD status (Hidiroglou, 1987; Hidiroglou and Karpinski, 1989). Therefore, the short duration of the experiment and the healthy initial vitD status also helped prevent a real vitD deficiency in our control groups.

The levels of the active metabolite 1,25vitD in serum, on the other hand, were neither influenced by irradiation nor by species difference. After 3 mo of observation, only a decrease of 1,25 levels in control groups could be observed. Therefore, the inexplicably higher serum 1,25vitD levels in irradiated goat kids found by Kovács et al. (2015) could not be confirmed. The production of $1,25 \mathrm{vitD}$ from $25 \mathrm{vitD}$ by the enzyme $1 \alpha$-OHase is inhibited by the final product 1,25 vitD, as well as by Ca and $\mathrm{P}$, and stimulated by calcitonin, IGF-I, and parathyroid hormone (Nesbitt and Drezner, 1993; Holick, 2008; Dittmer and Thompson, 2011; Jones, 2013). The levels of
$\mathrm{Ca}$ and $\mathrm{P}$ in serum remained stable in a normal range (Pugh, 2002) during the whole experiment and IGF-I increased in a similar way in all the groups due to the physiological growing process (Zofková, 2003). Consequently, neither the amount of the enzyme $1 \alpha-\mathrm{OHase}$ nor 24-OHase in the kidney was altered. In future studies, it would be interesting to analyze the reaction in an additional situation of reduced Ca supply.

Considering therefore that the difference in $25 \mathrm{vitD}$ status between the groups was not caused by a different degradation and the husbandry conditions and the feeding were identical for all groups, the difference must have been caused by the production with irradiation of the skin. These findings are in line with previous studies that showed a better vitD status in sheep exposed to UVB irradiation (Quarterman et al., 1964; Smith and Wright, 1980; Hidiroglou and Karpinski, 1989; Kovács et al., 2015) and show evidence of the parallelism to the endogenous vitD production in dairy cows (Hymøller et al., 2009; Hymøller and Jensen, 2010, 2012; Hymøller et al., 2017). Also, the lower content of 7DHC in the skin of the irradiated animals compared with the control group supports our hypothesis. This goes along with the findings described by Kovács et al. (2015) and is caused by the transformation of 7DHC into pre-D3, as it has been proven in vitro for human skin (Holick et al., 1981). On the other hand, we could not find an irradiation-dependent increase in the concentration of the photoproducts (pre-D3, lumisterol, tachysterol, vitD3) in skin samples. Kühn et al. (2015) investigated the effect of UVB irradiation in skin of chicks and found no significant effect on 7DHC concentrations (but a slight irradiation-dependent decrease), and an irradiation-dependent increase on vitD3 concentrations. An explanation for the lack of accumulation of the produced vitD3 in the analyzed skin samples is that it has been released to circulation (Holick et al., 1980). In fact, the amount of $7 \mathrm{DHC}$ in the skin parts most exposed to UVB irradiation (back and neck) was negatively correlated with the $25 \mathrm{vitD}$ serum level. The lack of an increase of lumisterol and tachysterol remains unclear, but it could be hypothesized that the amount of UVB reaching the skin layers, which can be influenced by factors like skin pigmentation or thickness as well as hair coat density, was not high enough for their production or that other storage forms such as suprasterol I, suprasterol II, or 5,6-transvitamin D3 are involved (Forrest and Fleet, 1985; Webb and Holick, 1988; Handel et al., 2016). To clarify interspecies differences in those storage forms, further studies are needed. So far, we could show that lambs have a higher concentration of tachysterol and goat kids have a higher concentration of lumisterol within their skin. Also, the influence of the amount of 
7DHC in the skin, as part of the cholesterogenic pathway, needs to be further investigated in both species. In fact, we could not confirm that sheep have 10 times lower concentration of 7DHC in their skin compared with goats as shown by Kohler et al. (2013) in adult animals, and for unclear reasons our 7DHC levels were higher compared with those measured in the study of Kovács et al. (2015).

\section{Effect of Vitamin D Status on Bone Metabolism, Ca Absorption, and Ca Homeostasis}

A sufficient vitD status, combined with a normal Ca availability, leads to the embedment of the minerals in the bone and these lead to an increase of BMD. In all groups BMD increased over the trial time, which is part of a normal physiological aging process (Liesegang et al., 2013), although the increase was higher in lambs than in goat kids. This agrees with the results of Kovács et al. (2015) and supports the suggestion of Liesegang and Risteli (2005) that growing sheep react faster in embedding minerals in the bone compared with growing goats. No difference between irradiated and control groups was seen in the BMD at the end of the experiment and the animals of the control groups did not show any signs of rickets or poor bone mineralization. This means that all the animals continued their normal bone growth and that the reduced vitD status in the control groups was not yet too low to influence bone formation (Van Saun, 2004; Dittmer et al., 2011; Dittmer and Thompson, 2011).

The concentrations of bone formation marker (OC) as well as bone resorption marker (SCL) in serum were higher in goat kids than in lambs, which leads to a higher bone turnover and conforms with reduced mineralization of the bones (Lips and van Schoor, 2011). Also, IGF-I and GH influence bone remodeling during the growth process. The pituitary gland produces and releases GH that stimulates the production of IGF-I in the liver and other tissues, which then increases osteoclastic and osteoblastic activity. It has been demonstrated in young men that IGF-I correlates well with bone turnover (Fatayerji and Eastell, 1999); therefore, it was not surprising that, as in Kovács et al. (2015), goat kids also had higher GH and IGF-I levels compared with lambs. However, this needs to be carefully interpreted because 2 different biases could be responsible for that significant interspecies difference: the pulsatile excretion of the 2 hormones during the day (which can also be affected by interspecies differences) and the high difference in sensitivity of the methods used for the different species.

In the gastrointestinal tract, we investigated the active Ca absorption with the background of a sufficient
Ca supply. Therefore, the paracellular absorption was probably sufficient to cover the Ca demand. Accordingly, even if goat kids had higher $\mathrm{AD}$ of Ca during the whole experiment, they did not have higher active $\mathrm{Ca}$ net fluxes compared with lambs. We detected an active Ca net absorption in rumen and an active Ca net secretion in duodenum, which goes along with previous studies (Schröder et al., 1999; Sidler-Lauff et al., 2010; Kovács et al., 2015). Ruminal Ca absorption plays an important role in Ca homeostasis in ruminants, but the underling mechanisms are still not fully understood. It was previously demonstrated that, as in our study, the active trans-epithelial $\mathrm{Ca}$ absorption is not influenced by 1,25vitD (Schröder et al., 1999; Sidler-Lauff et al., 2010; Wilkens et al., 2011, 2012), but can be increased for example by alimentary administration of anionic salts, short-chain fatty acids, or $\mathrm{Cl}$ (Leonhard-Marek et al., 2007; Wilkens et al., 2016). As all the groups received the same diet, the reason why the control group (GC) had an unexpected higher active ruminal Ca absorption compared with GUV cannot be explained. However, the higher active net $\mathrm{Ca}$ secretion in duodenum in GC conforms with the results of Kovács et al. (2015) and could be a mechanism to compensate for the excess of $\mathrm{Ca}$ absorbed in the rumen to keep the Ca blood level constant. This supports the theory of Schröder and Breves (2006) who showed that the net absorption in the forestomachs and abomasum is negatively correlated with the intestinal net $\mathrm{Ca}$ absorption in cows, indicating a kind of compensatory mechanism that still needs to be investigated. The differences between the groups that we found in goat kids but not in sheep also indicate that goats probably adapt faster through the intestine in a situation of challenged $\mathrm{Ca}$ homeostasis and profit more from intestinal Ca absorption compared with sheep (Wilkens et al., 2012; Kovács et al., 2015).

In the duodenum of monogastric animals, the effect of 1,25 vitD on the active $\mathrm{Ca}$ absorption is mediated by a VDR-dependent genomic action (Bronner, 2003), and in vitD deficient rats a reduction of VDR in duodenum was found (Zineb et al., 1998). In contrast, even if VDR was detected in the duodenum of ruminants (Boos et al., 2007; Riner et al., 2008), the transcellular Ca transport that is influenced by 1,25vitD is less important (Schröder et al., 1997; Sidler-Lauff et al., 2010; Wilkens et al., 2011). Indeed, we found no difference between the groups in VDR expression on protein level, probably also because the vitD status of the control group was not as low as in a situation of vitD deficiency.

Considering the $\mathrm{AD}$ of $\mathrm{P}$, we only found lower $\mathrm{AD}$ in goat kids compared with lambs. This agrees with previous studies that showed that in goats fecal P losses might be so high that apparent digestibility results are 
negative, but this does not reflect a negative true $\mathrm{P}$ digestibility. The amount of $\mathrm{AD}$ of $\mathrm{P}$ is linearly correlated with the dietary $\mathrm{P}$ intake, and the fecal $\mathrm{P}$ losses are also influenced by the dietary $\mathrm{P}$ intake, the salivary excretion, as well as the DMI and crude fiber content in feed (Bravo et al., 2003; Tayo et al., 2009).

The excretion of $\mathrm{Ca}$ and $\mathrm{P}$ through the kidneys was also not influenced by irradiation or vitD status. As already shown in earlier studies, in ruminants in contrast to monogastric animals, the kidneys are not a main site for the regulation of Ca homeostasis (Hoenderop et al., 2005; Herm et al., 2015).

In this study healthy animals with a good initial vitD status were used to demonstrate that the irradiation can prevent the drop of the vitD status even if the nutritional vitD supply is missing and therefore keep the healthy growing going, instead of curing an initial vitD deficiency, which is rare considering the currently used diets highly supplemented with vitD. In summary, during these experiment the animals were in a situation of challenged $\mathrm{Ca}$ homeostasis because of the growing process, but the $\mathrm{AD}$ of $\mathrm{Ca}$ and $\mathrm{P}$ as well as the $\mathrm{Ca}$ and $\mathrm{P}$ content in serum remained constant in both species over the whole time, and therefore the 25 vit D levels and the absorbed Ca were sufficient to permit an embedment in the bones and a normal growth with increasing of BMD. Even if the vitD status in the control groups was declining, the period of the experiment was not sufficient to really achieve a vitD deficiency and therefore no negative effects on Ca homeostasis were detected. However, effects of the declined vitD status on other physiological processes, for example, on the immune system or on cell differentiation (Holick, 2004; Dittmer and Thompson, 2011), which were not analyzed in this study, cannot be excluded. In ruminants, it was demonstrated that vitD status interferes with reproductive performance in an observational study done in a wild Soay sheep population (Handel et al., 2016), and that vitD improves the immune function in cows (Nelson et al., 2010; Vieira-Neto et al., 2017). Therefore, future studies should include effects on fertility and the immune system.

\section{CONCLUSIONS}

In conclusion, we could demonstrate that, like cows, growing dairy goats and sheep are able to compensate a vitD-reduced diet by producing vitD within their skin while exposed to UVB irradiation and therefore to keep a high vitD status and a balanced Ca homeostasis. In contrast, the vitD status of the control groups with no UVB exposure dropped, but not enough to induce an actual vitD deficiency and therefore no effects on Ca homeostasis were yet detected. In future studies, with a prolonged observation time, it should be clarified which is actually the ideal vitD status in young sheep and goats to ensure a healthy growing process and a balanced Ca homeostasis and how much UVB irradiation is needed to achieve that goal with the practical consequences in livestock farming.

\section{ACKNOWLEDGMENTS}

The authors thank Ines Mittner, Susanne von Waldow, and Reto Mühlemann for their technical assistance. The laboratory work was partly performed using the logistics of the Centre for Clinical Studies at the Vetsuisse Faculty of the University of Zurich.

\section{REFERENCES}

Adams, J. S., T. L. Clemens, J. A. Parrish, and M. F. Holick. 1982 Vitamin-D synthesis and metabolism after ultraviolet irradiation of normal and vitamin-D-deficient subjects. N. Engl. J. Med. 306:722-725.

Agroscope. 2013. Fütterungsempfehlungen für Wiederkäuer (Grünes Buch). Accessed Aug. 5, 2014. http://www.agroscope.admin.ch/ futtermitteldatenbank/04834/index.html?lang=de. Agroscope, Posieux, Schweiz.

Boos, A., K. Riner, M. Hässig, and A. Liesegang. 2007. Immunohistochemical demonstration of vitamin $\mathrm{D}$ receptor distribution in goat intestines. Cells Tissues Organs 186:121-128.

Bravo, D., D. Sauvant, C. Bogaert, and F. Meschy. 2003. III. Quantitative aspects of phosphorus excretion in ruminants. Reprod. Nutr. Dev. 43:285-300.

Bronner, F. 2003. Mechanisms and functional aspects of intestinal calcium absorption. J. Exp. Zool. A Comp. Exp. Biol. 300A:47-52.

Dittmer, K. E. E. C. Firth, K. G. Thompson, J. C. Marshall, and H. T. Blair. 2011. Changes in bone structure of Corriedale sheep with inherited rickets: A peripheral quantitative computed tomography assessment. Vet. J. 187:369-373.

Dittmer, K. E., and K. G. Thompson. 2011. Vitamin D metabolism and rickets in domestic animals: A review. Vet. Pathol. 48:389-407.

Fatayerji, D., and R. Eastell. 1999. Age-related changes in bone turnover in men. J. Bone Miner. Res. 14:1203-1210.

Forrest, J. W., and M. R. Fleet. 1985. Lack of tanning in white Merino sheep following exposure to ultraviolet light. Aust. Vet. J. $62: 244-246$

Haddad, J. G., L. Y. Matsuoka, B. W. Hollis, Y. Z. Hu, and J. Wortsman. 1993. Human plasma transport of vitamin D after its endogenous synthesis. J. Clin. Invest. 91:2552-2555.

Handel, I., K. A. Watt, J. G. Pilkington, J. M. Pemberton, A. Macrae, P. Scott, T. N. McNeilly, J. L. Berry, D. N. Clements, D H. Nussey, and R. J. Mellanby. 2016. Vitamin D status predicts reproductive fitness in a wild sheep population. Sci. Rep. 6:18986.

Herm, G., A. S. Muscher-Banse, G. Breves, B. Schröder, and M. R. Wilkens. 2015. Renal mechanisms of calcium homeostasis in sheep and goats. J. Anim. Sci. 93:1608-1621.

Hidiroglou, M. 1987. Kinetics of intravenously administered 25-hydroxyvitamin D3 in sheep and the effect of exposure to ultraviolet radiation. J. Anim. Sci. 65:808-814.

Hidiroglou, M., and K. Karpinski. 1989. Providing vitamin D to confined sheep by oral supplementation vs ultraviolet irradiation. J. Anim. Sci. 67:794-802.

Hoenderop, J. G. J., B. Nilius, and R. J. M. Bindels. 2005. Calcium absorption across epithelia. Physiol. Rev. 85:373-422.

Holick, M. F., J. MacLaughlin, and S. Doppelt. 1981. Regulation of cutaneous previtamin D3 photosynthesis in man: Skin pigment is not an essential regulator. Science 211:590-593. 
Holick, M. F. 2004. Sunlight and vitamin D for bone health and prevention of autoimmune diseases, cancers, and cardiovascular disease. Am. J. Clin. Nutr. 80(Suppl.):1678S-1688S.

Holick, M. F. 2008. Sunlight, vitamin D and health: A D-lightful story. Solar Radiation and Human Health. The Norwegian Academy of Science and Letters. 147-166.

Holick, M. F., J. A. MacLaughlin, M. B. Clark, S. A. Holick, J. T. Potts Jr., R. R. Anderson, I. H. Blank, J. A. Parrish, and P. Elias. 1980. Photosynthesis of previtamin D3 in human skin and the physiologic consequences. Science 210:203-205.

Holick, M. F., N. M. Richtand, S. C. McNeill, S. A. Holick, J. E. Frommer, J. W. Henley, and J. T. Potts Jr.. 1979. Isolation and identification of previtamin D3 from the skin of rats exposed to ultraviolet irradiation. Biochemistry 18:1003-1008.

Horst, R. L., and E. T. Littledike. 1982. Comparison of plasma concentrations of vitamin D and its metabolites in young and aged domestic animals. Comp. Biochem. Physiol. B 73:485-489.

Horst, R. L., and T. A. Reinhardt. 1983. Vitamin D metabolism in ruminants and its relevance to the periparturient cow. J. Dairy Sci. 66:661-678.

How, K. L., H. A. W. Hazewinkel, and J. A. Mol. 1994. Dietary vitamin D dependence of cat and dog due to inadequate cutaneous synthesis of vitamin D. Gen. Comp. Endocrinol. 96:12-18.

Hymøller, L., and S. K. Jensen. 2010. Vitamin D3 synthesis in the entire skin surface of dairy cows despite hair coverage. J. Dairy Sci. 93:2025-2029.

Hymøller, L., and S. K. Jensen. 2012. 25-Hydroxycholecalciferol status in plasma is linearly correlated to daily summer pasture time in cattle at $56^{\circ} \mathrm{N}$. Br. J. Nutr. 108:666-671.

Hymøller, L., S. K. Jensen, P. Kaas, and J. Jakobsen. 2017. Physiological limit of the daily endogenous cholecalciferol synthesis from UV light in cattle. J. Anim. Physiol. Anim. Nutr. (Berl.) 101:215-221.

Hymøller, L., S. K. Jensen, H. Lindqvist, B. Johansson, M. O. Nielsen, and E. Nadeau. 2009. Supplementing dairy steers and organically managed dairy cows with synthetic vitamin D3 is unnecessary at pasture during exposure to summer sunlight. J. Dairy Res. 76:372378.

Jakobsen, J., S. K. Jensen, L. Hymøller, E. W. Andersen, P. Kaas, A Burild, and R. B. Jäpelt. 2015. Short communication: Artificial ultraviolet B light exposure increases vitamin D levels in cow plasma and milk. J. Dairy Sci. 98:6492-6498.

Jäpelt, R. B., T. Didion, J. Smedsgaard, and J. Jakobsen. 2011. Seasonal variation of provitamin D2 and Vitamin D2 in perennial ryegrass (Lolium perenne L.). J. Agric. Food Chem. 59:10907-10912.

Jones, G. 2013. Extrarenal vitamin D activation and interactions between vitamin D2, vitamin D3, and vitamin D analogs. Annu. Rev. Nutr. 33:23-44.

Kohler, M., F. Leiber, H. Willems, L. Merbold, and A. Liesegang. 2013. Influence of altitude on vitamin D and bone metabolism of lactating sheep and goats. J. Anim. Sci. 91:5259-5268.

Kovács, S., M. R. Wilkens, and A. Liesegang. 2015. Influence of UVB exposure on the vitamin D status and calcium homoeostasis of growing sheep and goats. J. Anim. Physiol. Anim. Nutr. (Berl.) 99:1-12.

Kühn, J., A. Schutkowski, F. Hirche, A. C. Baur, N. Mielenz, and G. I. Stangl. 2015. Non-linear increase of vitamin D content in eggs from chicks treated with increasing exposure times of ultraviolet light. J. Steroid Biochem. Mol. Biol. 148:7-13.

Leonhard-Marek, S., G. Becker, G. Breves, and B. Schröder. 2007. Chloride, gluconate, sulfate, and short-chain fatty acids affect calcium flux rates across the sheep forestomach epithelium. J. Dairy Sci. 90:1516-1526.

Liesegang, A., D. Hüttenmoser, J. Risteli, F. Leiber, M. Kreuzer, and M. Wanner. 2013. Influence of high-altitude grazing on bone metabolism of growing sheep. J. Anim. Physiol. Anim. Nutr. (Berl.) 97:58-66.

Liesegang, A., and J. Risteli. 2005. Influence of different calcium concentrations in the diet on bone metabolism in growing dairy goats and sheep. J. Anim. Physiol. Anim. Nutr. (Berl.) 89:113-119.
Lips, P., and N. M. van Schoor. 2011. The effect of vitamin D on bone and osteoporosis. Best Pract. Res. Clin. Endocrinol. Metab. 25:585-591.

MacLaughlin, J. A., R. R. Anderson, and M. F. Holick. 1982. Spectral character of sunlight modulates photosynthesis of previtamin D3 and its photoisomers in human skin. Science 216:1001-1003.

Morris, J. G. 1999. Ineffective vitamin D synthesis in cats is reversed by an inhibitor of 7-dehydrocholestrol- $\Delta 7$-reductase. J. Nutr. 129:903-908.

Nelson, C. D., J. D. Lippolis, T. A. Reinhardt, R. E. Sacco, J. L. Powell, M. E. Drewnoski, M. O'Neil, D. C. Beitz, and W. P. Weiss. 2016. Vitamin D status of dairy cattle: Outcomes of current practices in the dairy industry. J. Dairy Sci. 99:10150-10160.

Nelson, C. D., T. A. Reinhardt, T. C. Thacker, D. C. Beitz, and J. D. Lippolis. 2010. Modulation of the bovine innate immune response by production of 1 $\alpha, 25$-dihydroxyvitamin D3 in bovine monocytes. J. Dairy Sci. 93:1041-1049.

Nesbitt, T., and M. K. Drezner. 1993. Insulin-like growth factor-I regulation of renal 25-hydroxyvitamin D-1-hydroxylase activity. Endocrinology 132:133-138.

Norman, A. W. 2011. Vitamin D nutrition is at a crossroads. Public Health Nutr. 14:744-745.

Pugh, D. G. 2002. Sheep and Goat Medicine. 1st ed. W. B. Saunders Company, Philadelphia, PA

Quarterman, J.,. A. C. Dalgarno, and A. Adam. 1964. Some factors affecting the level of vitamin D in the blood of sheep. Br. J. Nutr. 18:79-89.

Riner, K., A. Boos, M. Hässig, and A. Liesegang. 2008. Vitamin D receptor distribution in intestines of domesticated sheep Ovis ammon f. aries. J. Morphol. 269:144-152.

Schröder, B., and G. Breves. 2006. Mechanisms and regulation of calcium absorption from the gastrointestinal tract in pigs and ruminants: Comparative aspects with special emphasis on hypocalcemia in dairy cows. Anim. Health Res. Rev. 7:31-41.

Schröder, B., I. Rittmann, E. Pfeffer, and G. Breves. 1997. In vitro studies on calcium absorption from the gastrointestinal tract in small ruminants. J. Comp. Physiol. B 167:43-51.

Schröder, B., S. Vössig, and G. Breves. 1999. In vitro studies on active calcium absorption from ovine rumen. J. Comp. Physiol. B 169:487-494.

Sidler-Lauff, K., A. Boos, M. Kraenzlin, and A. Liesegang. 2010. Influence of different calcium supplies and a single vitamin D injection on vitamin $\mathrm{D}$ receptor and calbindin D9k immunoreactivities in the gastrointestinal tract of goat kids. J. Anim. Sci. 88:3598-3610.

Smith, B. S., and H. Wright. 1980. The response of serum 25-hydroxyvitamin D concentrations to vitamin D intake and insolation in sheep. Br. J. Nutr. 43:533-540.

Stangl, G. I. 2014. Die Verdauung. Pages 27-46 in Tiernährung. 14th ed. Kirchgessner, M.; Stangl, G.I.; Schwarz, F.J.; Roth, F.X.; Südekum, K.H.; Eder, K. ed. DLG-Verlag GmbH, Frankfurt am Main, Germany.

Tayo, G. O., S. X. Tang, Z. L. Tan, Z. H. Sun, M. Wang, C. S. Zhou, and X. F. Han. 2009. Determination of endogenous faecal phosphorus loss in goats. Arch. Anim. Nutr. 63:104-111.

Tryfonidou, M. A., M. S. Holl, M. Vastenburg, M. A. OosterlakenDijksterhuis, D. H. Birkenhäger-Frenkel, W. E. van den Brom, and H. A. W. Hazewinkel. 2003. Hormonal regulation of calcium homeostasis in two breeds of dogs during growth at different rates. J. Anim. Sci. 81:1568-1580.

Van Saun, R. J. 2004. Vitamin D-responsive rickets in neonatal lambs. Can. Vet. J. 45:841-844.

Van Soest, P. J., J. B. Robertson, and B. A. Lewis. 1991. Methods for dietary fiber, neutral detergent fiber, and nonstarch polysaccharides in relation to animal nutrition. J. Dairy Sci. 74:3583-3597.

Vieira-Neto, A., I. R. P. Lima, F. Lopes Jr., C. Lopera, R. Zimpel, L. D. P. Sinedino, K. C. Jeong, K. Galvão, W. W. Thatcher, C. D. Nelson, and J. E. P. Santos. 2017. Use of calcitriol to maintain postpartum blood calcium and improve immune function in dairy cows. J. Dairy Sci. 100:5805-5823. 
Webb, A. R., and M. F. Holick. 1988. The role of sunlight in the cutaneous production of vitamin D3. Annu. Rev. Nutr. 8:375-399.

Weber, G. M., A.-K. M. Witschi, C. Wenk, and H. Martens. 2014. Triennial Growth Symposium - Effects of dietary 25-hydroxycholecalciferol and cholecalciferol on blood vitamin D and mineral status, bone turnover, milk composition, and reproductive performance of sows. J. Anim. Sci. 92:899-909.

Weiss, W. P., E. Azem, W. Steinberg, and T. A. Reinhardt. 2015. Effect of feeding 25-hydroxyvitamin D3 with a negative cation-anion difference diet on calcium and vitamin D status of periparturient cows and their calves. J. Dairy Sci. 98:5588-5600.

Wilkens, M. R., C. Kunert-Keil, H. Brinkmeier, and B. Schröder. 2009 Expression of calcium channel TRPV6 in ovine epithelial tissue. Vet. J. 182:294-300.

Wilkens, M. R., N. Mrochen, G. Breves, and B. Schröder. 2011. Gastrointestinal calcium absorption in sheep is mostly insensitive to an alimentary induced challenge of calcium homeostasis. Comp. Biochem. Physiol. B Biochem. Mol. Biol. 158:199-207.
Wilkens, M. R., C. Praechter, G. Breves, and B. Schröder. 2016. Stimulating effects of a diet negative in dietary cation-anion difference on calcium absorption from the rumen in sheep. J. Anim. Physiol. Anim. Nutr. (Berl.) 100:156-166.

Wilkens, M. R., J. Richter, D. R. Fraser, A. Liesegang, G. Breves, and B. Schröder. 2012. In contrast to sheep, goats adapt to dietary calcium restriction by increasing intestinal absorption of calcium. Comp. Biochem. Physiol. A Mol. Integr. Physiol. 163:396-406.

Zineb, R., B. Zhor, W. Odile, and R.-R. Marthe. 1998. Distinct, tissue-specific regulation of vitamin d receptor in the intestine, kidney, and skin by dietary calcium and vitamin D. Endocrinology 139:1844-1852.

Zofková, I. 2003. Pathophysiological and clinical importance of insulinlike growth factor-I with respect to bone metabolism. Physiol. Res. $52: 657-679$ 